\title{
Role of Resilience in Burden and Perceived Public Stigma among Primary Caregivers of
} Psychiatric Patients

\author{
Farah Saleem ${ }^{1}$, Kehkashan Arouj ${ }^{2}$, Sabir Zaman ${ }^{3}$, Azmat Shaheen ${ }^{4}$
}

\section{Abstract}

The current study intended to find out the role of resilience on perceived public stigma and burden among primary caregivers of the psychiatric patients. The current study highlighted the psychological health of caregivers. A cross sectional study was conducted in region of Islamabad and Rawalpindi, Pakistan. A total of 250 caregivers participated in the study, whom 125 were male and 125 were female caregivers, age range was $25-60$ years $(M=31.61, S D=5.93)$. The data was collected from public and private hospitals. Three scales were used for data collection. The resilience was measured through Urdu translated resilience scale, public stigma was assessed by using Urdu version of perceived public stigma, and Burden was measured through interview. The result showed that resilience was negatively associated with burden and perceived public stigma $(p<0.01)$. Further, the multiple regression showed that resilience acted as moderator between public stigma and burden $(\beta=-1.02, p<.001)$. The result supported a positive association between public stigma, burden and resilience among caregivers of psychiatric patients.

Key Words: Public Stigma, Resilience, Burden, Psychiatric Patients, Caregivers

Received: 04 December 2021; Revised Received: 13 December 2021; Accepted: 28 December 2021

${ }^{1} \mathrm{MS}$ Scholar, Department of Psychology, International Islamic University, Islamabad, Pakistan.

${ }^{2}$ Assistant Professor, Department of Psychology, International Islamic University, Islamabad, Pakistan.

${ }^{3}$ Lecturer, Department of Psychology, International Islamic University, Islamabad, Pakistan.

${ }^{4}$ Clinical Psychologist/Senior Lecturer, Dr. Akbar Niazi Teaching Hospital Barakahu, Islamabad, Pakistan.

\section{Corresponding Author Email:}

sabir.zaman@iiu.edu.pk

\section{Introduction}

Caring for any patient involves significant resources, but the demands of these resources may increase in patients with psychiatric disorders (Basheer et al., 2015). These demands are implied for psychological health of caregivers. The primary caregivers are considered to be the backbone of the family system throughout the world particular in Asian family system. They may not only responsible for financial support but may also provide moral courage to the patient with psychiatric problems. Patients with mental health problems are fully dependent on others particular on primary caregivers such as parents, spouses, siblings and close relatives (Penning \& Wu, 2016). This responsibility may not only affect the physical and mental health; this gradually becomes a burden but may also affect resilience of the primary caregivers who are involved in caring of psychiatric patients. Statistics showed that the number of mental illness cases in South Asian region increased each year. According to $\mathrm{WHO}$, mental illness is $4 \%$ more than total burden of disease, and this rate is higher in women. It has been revealed that about 24 million people need psychiatric assistance. However, the allocated resources are not sufficient for the treatment and screening of mental health disorders (WHO, 2010). It has

This article is distributed under the terms of the Creative Commons Attribution Non Commercial 4.0 License (http://www.creativecommons.org/licenses/by-nc/4.0/) which permits nonCommercial use, reproduction and distribution of the work without further permission provided the original work is attributed as specified. 
been revealed by $\mathrm{WHO}$, that Pakistan is the only country, where the mental health professionals are lower than other regions of the world, the estimated range of psychiatrists about 0.19 per 100,000 persons (WHO, 2021).

It is observed that caring for mentally ill family members badly affects the caregivers' mental health. Parents who are caring for children with severe mental illness have hyperactive cortisol profiles, which indicates a chronic stress level compared to parents of individuals without a severe mental illness (Barker et al., 2012). Similarly, the caregivers of patients with mental illness also appear more prone to depression as a consequence of their experiences. Various research findings have also shown that tiredness, sadness, constant stress, uncertainty and frustration are the common feelings of burden expressed by caregivers (Johansson et al., 2010).

In many cases, the sufferers of severe mental disorders required a long-term care. Thus, care and responsibility are provided through informal ways by primary caregivers. Unfortunately, lack of resources and specialized trained individuals for caring and treatment of this population leads to a huge burden of mental health issues in Pakistan. Due to lack of awareness of general public, lack of government involvement, nonprofessionals provide psychosocial intervention which may fill the gap to some extent (Sikander, 2020) Previous studies have expounded that caregivers are considerably important in the treatment, prognosis as well as lessening the relapse, self-harm and rates of hospital admission (Haddad et al., 2014). Though, caring of the mentally ill patients may also some negative impact on psychological health of caregivers. Those who caring the severe mentally ill peoples, have high level of cortisol which may lead to chronic stress (Barker et al., 2012). Furthermore, it has been shown that caregivers involved in patients with severe psychological disorder may have tiredness, constant stress, frustration, uncertainty and sadness and common feeling of burden expression (Johansson et al., 2010).

Public stigma is the negative view of general public that they hold against specific groups (Corrigan, 2004). The perceived public stigma from others (i.e. negative views from others if someone sought treatment) is one of the considerable barrier in the treatment of mental problems among young adults (Eisenberg et al., 2007). Findings of National Comorbidity Survey showed that approximately one-fifth individuals have dropped their mental health treatment due to perceived public stigma (Mojtabai et al., 2011). Moreover, it has also been revealed that perceived public stigma is not only major barrier to treatment seeking but it may also aggravate anxiety, depressive symptoms, social isolation and substance abuse (Britt et al., 2008; Keyes et al., 2010). On other side, caregivers burden is considered as the repercussion raises in caregivers in the form of social, physical and emotional distress, and these difficulties may cause financial burden and responsibilities lacking in caregivers (Zarit et al., 1986). The sociodemographic profile of caregiving has a link with caregiver burden. Previous studies shown that elder and female caregivers with depressive symptoms and perceived public stigma are more likely experience high level of caregiver burden (Hasson-Ohayon et al., 2011). Moreover, the other factors such as availability of social support, patient's behavioral problems, spending more time with patients have also been associated with caregiver burden (Rodrigo et al., 2013).

Resilience is the key variable in which the individual becomes able to deal with challenges. In nursing professionals, resilience is considered a psychological phenomenon referred towards adaptive and effective coping strategies implied when 
someone face hardship, loss and adversity (Wilks \& Croom, 2008). Majority of researchers hold that positive adaptation and adversity are the two core characteristics that might exist in the resilience (Fletcher \& Sarkar, 2013). Thus, caregiver resilience can be considered adversity while providing caring to mental illness individuals. Previous studies reported that individuals who are more resilient have better mental and physical health, perceived social support from family or friends and have the ability to cope with adversity (O'Rourke et al., 2011). The current study was hypothesized to find out the role of resilience on perceived public stigma and burden of primary caregiver of psychiatric patients.

\section{Method}

\section{Research Design}

A cross sectional research design was used to explore the relationship of resilience between public stigma and burden of primary caregivers of psychiatric patients.

\section{Participants}

Sample consisted of 250 caregivers of patients with severe mental illness, where 125 were male and 125 were female caregivers with an age range of 25 years to 60 years $(M=34.15, S D=12.80)$, married females were $171(68.4 \%)$, and single were 79 $(31.6 \%)$. Caregivers were taken for clients with different categories of symptoms like Depression, Anxiety, Schizophrenia, Bipolar disorder, Conversion disorder, Post traumatic Stress disorder and Obsessive-Compulsive disorder. In this study, caregivers were comprised of parents, siblings, spouses and children. The participants were selected through purposive sampling from different psychiatric settings of Rawalpindi and Islamabad.

\section{Procedure}

The participants were taken from different public and private hospitals of Rawalpindi and Islamabad. Permission was taken from heads of the concerned departments. All the information and purpose of the study were explained to the caregivers. Moreover, confidentiality was also ensured, those who showed participation willingness in the study were asked to sign consent form and complete the self-administered questionnaires. The demographic information was taken from caregivers in local language, and in the last, they were thanked for giving their time and responses.

\section{Measures}

Urdu translated version of Zarit Burden Interview was used for the assessment of caregiver's burden. The scale was developed by Zarit and consisted of 22 items in a Likert type range from 0-4 (Zarit et al., 1980). The scale has high reliability and validity (Muazzam \& Javed, 2013; Mustafa \& Zafar, 2015). The burden interview is scored by summing the responses of the individual items. The score range is from 0 to 88 and higher scores indicate greater caregiver distress. Range of obtained scores were found as from 0 to 20 showed no burden to little burden, 21 to 40 reflected mild to moderate burden, 41 - 60 demonstrated a moderate to severe degree 61 to 88 appears with a severe level of burden.

For perceived public stigma assessment, an Urdu translated Perceived DevaluationDiscrimination Scale was used. The internal consistency of scale ranging from $\alpha$ validity 0.86 to 0.88 , test-retest reliability $=0.93$ (Link et al., 1987). The scale consists of 12 items half of which are reverse scored with five-point Likert ranging from "strongly Agree" to "strongly Disagree". Higher scores indicate more public stigma. Furthermore, Conner-Davidson Resilience Scale (CD_RISC) was used to measure the resilience of caregivers, it consists of 25 items of five-point Likert scale. The total possible scores range from 0-100 (Connor et al., 2003). The scale has good reliability $\alpha$ 
0.94, an Urdu translated version was used for current study (Murtaza et al., 2016)

\section{Results}

Table 1

Demographic Characteristics of Study Sample $(N=250)$

\begin{tabular}{|c|c|c|}
\hline Variables & Categories & $(N) \%$ \\
\hline Age & $21-30$ & $112(44.8)$ \\
\hline$M=34.15, S D=12.80$ & $31-40$ & $75(30.0)$ \\
\hline \multirow[t]{2}{*}{ Min 21, Max 60} & $41-50$ & $51(20.4)$ \\
\hline & $51-60$ & $12(4.8)$ \\
\hline \multirow[t]{2}{*}{ Gender } & Male & $125(50)$ \\
\hline & Female & $125(50)$ \\
\hline \multirow[t]{2}{*}{ Marital Status } & Married & $171(68.4)$ \\
\hline & Single & $79(31.6)$ \\
\hline \multirow[t]{2}{*}{ Socio-economic } & Lower & $52(20.8)$ \\
\hline & Middle & $198(79.2)$ \\
\hline \multirow[t]{7}{*}{ Disorder } & Depression & $78(31.1)$ \\
\hline & Anxiety & $54(21.4)$ \\
\hline & Schizophrenia & $28(11.2)$ \\
\hline & Bipolar & $38(15.2)$ \\
\hline & Conversion & $21(8.4)$ \\
\hline & PTSD & $17(6.8)$ \\
\hline & OCD & $14(5.6)$ \\
\hline \multirow[t]{7}{*}{ Hospital } & Benazir Bhutto Hospital (BBH) & $80(32.0)$ \\
\hline & Capital Hospital & $55(22.0)$ \\
\hline & Holy Family Hospital & $15(6.0)$ \\
\hline & Shifa International Hospital & $10(4.0)$ \\
\hline & $\begin{array}{l}\text { Pakistan Institute of Medical Science } \\
\text { (PIMS) }\end{array}$ & $40(16.0)$ \\
\hline & Federal Government Services Hospital & $30(12.0)$ \\
\hline & Others & $20(8.0)$ \\
\hline \multirow{4}{*}{ Relationship with patient } & Parents & $80(32.0)$ \\
\hline & Spouses & $36(14.4)$ \\
\hline & Sibling & $85(34.0)$ \\
\hline & Children & $49(19.6)$ \\
\hline \multirow[t]{2}{*}{ Time with Patients } & $>12$ hours & $122(49.8)$ \\
\hline & $<12$ hours & $128(51.2)$ \\
\hline
\end{tabular}

Table 1 showed the socio-demographic characteristics of caregivers. The data was obtained from different hospitals and caregivers providing caring to the different psychological disorder patients. Table showed data related to demographics of caregivers. 


\section{Table 2}

Correlation Coefficient of Perceived Public Stigma, Resilience Scale and Burden Interview $(N=250)$

\begin{tabular}{|c|c|c|c|}
\hline Variables & 1 & 2 & 3 \\
\hline 1. Burden Interview & - & $0.38^{* *}$ & $-0.60^{* *}$ \\
\hline 2. Perceived Public Stigma & & - & $-0.43^{* *}$ \\
\hline 3.Resilience Scale & & & - \\
\hline
\end{tabular}

$* * p<.01$

Table 2 showed that BI significantly and positively correlated with perceived public stigma (0.38), while Burden interview have negatively correlated with Resilience Scale (-
0.60). Similarly, Burden interview and perceived public stigma have negative correlation with resilience scale.

\section{Table 3}

Moderating role of Resilience on Perceived Public Stigma and Burden among Primary Care Givers of Psychiatric Patients $(N=250)$

\begin{tabular}{lllll}
\hline & \multicolumn{3}{c}{ BI } \\
\cline { 2 - 5 } Variables & Model-1B & Model-2B & $\boldsymbol{B}$ & Model3 \\
\hline Constant & 9.36 & $51.72^{* * *}$ & 9.86 & 95 \% CI \\
PPS & $.86^{* * *}$ & $.34 * *$ & $1.30^{* * *}$ & {$[-12.43,32.16]$} \\
RS & & $-.43^{* * *}$ & $.496 * 1.79]$ \\
PPS*RS & & & $-.026^{* * *}$ & {$[.06, .87]$} \\
$\mathrm{R}^{2}$ & $.14 * * *$ & $.38^{* * *}$ & $.42^{* * *}$ & {$[-.03,-.01]$} \\
$\mathrm{F}$ & $42.73^{* * *}$ & $75.71 * * *$ & $60.89 * * *$ & \\
\hline
\end{tabular}

Note, $* * * p<.001, * * p<.01, * p<.05: \mathrm{BI}=$ Burden interview, $\mathrm{LS}=$ Life Satisfaction, $\mathrm{PPS}=$ Perceived Public Stigma, $\mathrm{RS}=$ Resilience scale, $C I=$ Confidence Interval.

Table 3 showed that resilience has significantly a moderating effect on perceived public stigma and burden $(\beta=-$

\section{Discussion}

The current study aimed to find out the role of resilience on perceived stigma and burden on primary care givers of psychiatric patients. The result showed in Table 2 a significant negative correlation of resilience with perceived public stigma and burden. Some previous literature may provide support to the result of the current study. It was revealed in a study that caregivers with high resilience would experience low burden (Gaugler et al., 2007). Moreover, not only resilience play an
1.02, $p<.001), \mathrm{R}^{2}$ value showed $42 \%$ variance, $F(60.89)$ and $p<.001$.

important role in physical and psychological health, but other social support may also have role in protecting the mental and physical health (Banyard et al., 2017; Won, 2012). Similarly, a study revealed that resilience is an important mediator between caregivers burden and distress (Ruisoto et al., 2020). However, some of the studies were in contrast with the result of current study. Frazier et al. (2004) revealed that social support and resilience have not direct relationship with burden of caregivers. 
Secondly, it was hypothesized that resilience would play a moderating effect on public stigma and burden. The result of the present study showed resilience has moderating effect on public stigma and burden as showed in table 3. The moderator hypothesis successfully proved that resilience reduces the strength of burden and perceived public stigma. The findings are consistent with previous literature. A study explored that perceived social support and resilience play a significant role in caregivers burden, but resilience has no moderating role (Ong et al., 2018). Furthermore, a study found that social support was a moderator of resilience that relieved psychological and physical overload caused by stress (Dias et al., 2015). It has been revealed in a study that resilience was not vulnerable to stress, but they may able to cope and recover the negative events (Cowan et al., 1996). Many studies reported that resilient people have strong mental and physical health, they gain social support from family members and friend and had ability to

\section{Conflict of Interest}

There is no conflict of interest among authors.

\section{References}

Banyard, V., Hamby, S., \& Grych, J. (2017). Health effects of adverse childhood events: Identifying promising protective factors at the intersection of mental and physical well-being. Child Abuse \& Neglect, 65, 88-98.

Barker, E. T., Greenberg, J. S., Seltzer, M. M., \& Almeida, D. M. (2012). Daily stress and cortisol patterns in parents of adult children with a serious mental illness. Health Psychology, $31(1)$, 130. https://doi.org/https://doi.org/10.103 7/a0025325 cope with adversity (Jonker \& Greeff, 2009; O'Rourke et al., 2010). Another study showed that caregiver burden inversely associated with caregivers' resilience (Mulud \& McCarthy, 2017). In addition, studies revealed that caregivers of elder people with Alzheimer, and female caregivers of mental illness may have strong mental health and resilience and perceived adequate support (Cassidy et al., 2014; Scott, 2013; Zauszniewski et al., 2009).

\section{Conclusion}

The current finds out that resilience plays a significant role in reducing the burden and perceived public stigma of the primary caregivers of the psychiatric patients. The study showed a significant positive correlation between burden and perceived public stigma, while these two have negative association with resilience. Hence, resilience is a moderator in public stigma and burden among caregivers of psychiatric patients.

\section{Source of Funding}

The authors declared no source of funding.

Basheer, S., Anurag, K., Garg, R., Kumar, R., \& Vashisht, S. (2015). Quality of life of caregivers of mentally ill patients in a tertiary care hospital. Industrial Psychiatry Journal, 24(2), 144. https://doi.org/doi: 10.4103/09726748.181721

Britt, T. W., Greene-Shortridge, T. M., Brink, S., Nguyen, Q. B., Rath, J., Cox, A. L., Hoge, C. W., \& Castro, C. A. (2008). Perceived stigma and barriers to care for psychological treatment: Implications for reactions to stressors in different contexts. Journal of Social and Clinical Psychology, 27(4), 317-335. 
https://doi.org/https://doi.org/10.152 1/jscp.2008.27.4.317

Cassidy, T., Giles, M., \& McLaughlin, M. (2014). Benefit finding and resilience in child caregivers. British Journal of Health Psychology, 19(3), 606-618. https://doi.org/ https://doi.org/10.1111/bjhp.12059

Connor, K. M., Davidson, J. R., \& anxiety. (2003). Development of a new resilience scale: The ConnorDavidson resilience scale (CDRISC). Depression, 18(2), 76-82. https://doi.org/https://doi.org/10.100 2/da.10113

Corrigan, P. (2004). How stigma interferes with mental health care. American Psychologist, $\quad$ 59(7), 614. https://doi.org/https://doi.org/10.103 7/0003-066X.59.7.614

Cowan, P. A., Cowan, C. P., Schulz, M. S. J. S., coping, children, r. i., \& families. (1996). Thinking about risk and resilience in families. (1st ed).

( Psychology Press)

Dias, R., Santos, R. L., Sousa, M. F. B. d., Nogueira, M. M. L., Torres, B., Belfort, T., Dourado, M. C. N., \& psychotherapy. (2015). Resilience of caregivers of people with dementia: a systematic review of biological and psychosocial determinants. Trends in Psychiatry, 37, 12-19. https://doi.org/https://doi.org/10.159 0/2237-6089-2014-0032

Eisenberg, D., Golberstein, E., \& Gollust, S. E. (2007). Help-seeking and access to mental health care in a university student population. Medical Care, 594-601.

Fletcher, D., \& Sarkar, M. (2013). Psychological resilience. European Psychologist.

https://doi.org/https://doi.org/10.102 7/1016-9040/a000124
Frazier, P. A., Tix, A. P., \& Barron, K. E. (2004). Testing moderator and mediator effects in counseling psychology research. Journal of Counseling Psychology, 51(1), 115. https://doi.org/ https://doi.org/10.1037/00220167.51.1.115

Gaugler, J. E., Kane, R. L., \& Newcomer, R. (2007). Resilience and transitions from dementia caregiving. The Journals of Gerontology, 62(1), P38P44.

https://doi.org/https://doi.org/10.109 3/geronb/62.1.P38

Haddad, P. M., Brain, C., \& Scott, J. (2014). Nonadherence with antipsychotic medication in schizophrenia: challenges and management strategies. Patient related outcome measures, 5, 43. https://doi.org/doi: 10.2147/PROM.S42735

Hasson-Ohayon, I., Levy, I., Kravetz, S., Vollanski-Narkis, A., \& Roe, D. (2011). Insight into mental illness, self-stigma, and the family burden of parents of persons with a severe mental illness. Comprehensive Psychiatry, 52(1), 75-80. https://doi.org/https://doi.org/10.101 6/j.comppsych.2010.04.008

Johansson, A., Anderzen-Carlsson, A., Åhlin, A., \& Andershed, B. (2010). Mothers' everyday experiences of having an adult child who suffers from long-term mental illness. Issues in Mental Health Nursing, 31(11), 692-699.

https://doi.org/https://doi.org/10.310 9/01612840.2010.515768

Jonker, L., \& Greeff, A. P. (2009). Resilience factors in families living with people with mental illnesses. Journal of Community Psychology, 37(7), 859$873 . \quad$ https://doi.org/ https://doi.org/10.1002/jcop.20337 
Keyes, K. M., Hatzenbuehler, M. L., McLaughlin, K. A., Link, B., Olfson, M., Grant, B., \& Hasin, D. (2010). Stigma and treatment for alcohol disorders in the United States. American Journal of Epidemiology, 172(12), 1364-1372. https://doi.org/ https://doi.org/10.1093/aje/kwq304

Link, B. G., Cullen, F. T., Frank, J., \& Wozniak, J. F. (1987). The social rejection of former mental patients: Understanding why labels matter. American journal of Sociology, 92(6), 1461-1500.

Mojtabai, R., Olfson, M., Sampson, N. A., Jin, R., Druss, B., Wang, P. S., Wells, K. B., Pincus, H. A., \& Kessler, R. C. (2011). Barriers to mental health treatment: results from the National Comorbidity Survey Replication. Psychological medicine, 41(8), 17511761.

https://doi.org/https://doi.org/10.101 7/S0033291710002291

Muazzam, A., \& Javed, S. (2013). Predictors of caregiver's burden: interplay of physical and emotional health and perceived hope in children with thalassemia and hemophilia. Pakistan Journal of Social and Clinical Psychology, 11(2), 36.

Mulud, Z. A., \& McCarthy, G. (2017). Caregiver burden among caregivers of individuals with severe mental illness: Testing the moderation and mediation models of resilience. Archives of Psychiatric Nursing, 31(1), 24-30. https://doi.org/https://doi.org/10.101 6/j.apnu.2016.07.019

Murtaza, G., Sultan, S., Ahmed, F., \& Mustafa, G. J. J. A. E. B. S. (2016). Exploring construct validity of Resilience Scale in Pakistani youth. Journal of Applied Environmental and Biological Sciences, 6, 79-83.
Mustafa, A. B., \& Zafar, U. (2015). Frequency of family burden among caregivers of patients with schizophrenia. Journal of Sheikh Zayad Medical College, 6, 853-856.

O'Rourke, N., Claxton, A., Kupferschmidt, A. L., Smith, J. Z., \& Beattie, B. L. (2011). Marital idealization as an enduring buffer to distress among spouses of persons with Alzheimer disease. Journal of Social Personal Relationships, 28(1), 117-133. https://doi.org/https://doi.org/10.117 7/0265407510386135

O'Rourke, N., Kupferschmidt, A. L., Claxton, A., Smith, J. Z., Chappell, N., \& Beattie, B. L. (2010). Psychological resilience predicts depressive symptoms among spouses of persons with Alzheimer disease over time. Aging Mental Health, 14(8), 984-993. https://doi.org/DOI: 10.1080/13607863.2010.501063

Ong, H. L., Vaingankar, J. A., Abdin, E., Sambasivam, R., Fauziana, R., Tan, M.-E., Chong, S. A., Goveas, R. R., Chiam, P. C., \& Subramaniam, M. (2018). Resilience and burden in caregivers of older adults: moderating and mediating effects of perceived social support. BMC Psychiatry, 18(1), 1-9. https://doi.org/https://doi.org/10.118 6/s12888-018-1616-z

World Health Organization (2010). Mental health and development: targeting people with mental health conditions as a vulnerable group. In Mental health and development: targeting people with mental health conditions as a vulnerable group (pp. 74).

World Health Organization (2021). WHO Pakistan celebrates World Mental Health Day. http://www.emro.who.int/pak/pakista n-news/who-pakistan-celebrates- 
world-mental-health-

day.html\#: :text=On\%20World $\% 20$

Mental\%20Health\%20Day,Stress\%2

0Management\%20Unit\%20(CISMU)

Penning, M. J., \& Wu, Z. (2016). Caregiver stress and mental health: Impact of caregiving relationship and gender. The Gerontologist, 56(6), 1102-1113

Rodrigo, C., Fernando, T., Rajapakse, S., De Silva, V., \& Hanwella, R. (2013). Caregiver strain and symptoms of depression among principal caregivers of patients with schizophrenia and bipolar affective disorder in Sri Lanka. International Journal of Mental Health Systems, 7(1), 1-5. https://doi.org/https://doi.org/10.118 6/1752-4458-7-2

Ruisoto, P., Contador, I., Fernandez-Calvo, B., Serra, L., Jenaro, C., Flores, N., Ramos, F., Rivera-Navarro, J. J. A. o. g., \& geriatrics. (2020). Mediating effect of social support on the relationship between resilience and burden in caregivers of people with dementia. Archives of Gerontology Geriatrics, 86, 103952.

Scott, C. B. (2013). Alzheimer's disease caregiver burden: Does resilience matter? Journal of Human Behavior in the Social Environment, 23(8), 879-892.

https://doi.org/https://doi.org/10.108 0/10911359.2013.803451

Sikander, S. (2020). A letter from... Pakistan. In: Elsevier Sci Ltd the Boulevard Lane, Kidlington, Oxford OX5 1GB.

Wilks, S. E., \& Croom, B. (2008). Perceived stress and resilience in Alzheimer's disease caregivers: Testing moderation and mediation models of social support. Aging Mental Health, 12(3), 357-365. https://doi.org/https://doi.org/10.108 0/13607860801933323
Won, H. J. (2012). The impact of social support on caregiver burden in dementia 서울대학교 대학원].

Zarit, S. H., Reever, K. E., \& Bach-Peterson, J. (1980). Relatives of the impaired elderly: correlates of feelings of burden. The Gerontologist, 20(6), 649-655.

https://doi.org/https://doi.org/10.109 3/geront/20.6.649

Zarit, S. H., Todd, P. A., \& Zarit, J. M. (1986). Subjective burden of husbands and wives as caregivers: A longitudinal study. The Gerontologist, 26(3), 260-266. https://doi.org/https://doi.org/10.109 3/geront/26.3.260

Zauszniewski, J. A., Bekhet, A. K., \& Suresky, M. J. (2009). Effects on resilience of women family caregivers of adults with serious mental illness: The role of positive cognitions. Archives of Psychiatric Nursing, 23(6), 412-422. https://doi.org/https://doi.org/10.101 6/j.apnu.2008.12.004 